\section{GIP and the metabolic response to carbohydrate and fat}

Dear Sir,

In the article by Collier et al. [1], it was concluded that 'fat-stimulated GIP secretion does not potentiate glucose-induced insulin secretion, even in the presence of elevated blood glucose levels.' This conclusion is in contradiction to the results of several studies [2-8]. All these studies report significant stimulation of insulin secretion by oral fat in the presence of elevated blood glucose levels.

The reason for the negative findings in the study of Collier et al. [1] was the fact that a bolus injection of $5 \mathrm{~g}$ glucose was used which led to only a small and very short-lasting rise of glucose and insulin levels, in contrast to the effect of a continuous glucose infusion or an oral glucose load. Therefore, they are hardly justified in concluding from their negative finding after a bolus injection of $5 \mathrm{~g}$ glucose that "fatstimulated GIP secretion does not potentiate glucose-induced insulin secretion'. It may be true 'that GIP is not the sole gut factor responsible for potentiating insulin secretion' as suggested by several recent studies (including some from our laboratory), but Collier et al. do not illuminate this problem.

Finally, in their Discussion, regarding the influence of insulin and glucose on GIP plasma levels, Collier et al. quote a study by Pederson and Brown [9]. This study, however, does not address itself to the problem under discussion at all. Instead, they should refer to our study [10].

Yours sincerely,

W. Creutzfeldt

\section{References}

1. Collier GR, McLean A, O'Dea K (1984) Effect of co-ingestion of fat on the metabolic responses to slowly and rapidly absorbed carbohydrate. Diabetologia 26: $50-54$

2. Cleator IGM, Gourlay RH (1975) Release of immunoreactive gastric inhibitory polypeptide (IR-GIP) by oral ingestion of food substances. Am J Surg 130: 128-135

3. Crockett SE, Cataland S, Falko JM, Mazzaferri EL (1976) The insulinotropic effect of endogenous gastric inhibitory polypeptide in normal subjects. J Clin Endocrinol Metab 42: 1098-1103

4. Ross SA, Dupré J (1978) Effects of ingestion of triglyceride or galactose on secretion of gastric inhibitory polypeptide and on responses to intravenous glucose in normal and diabetic subjects. Diabetes 27: 327-333

5. Ebert R, Frerichs H, Creutzfeldt W (1979) Impaired feedback control of fat induced gastric inhibitory polypeptide (GIP) secretion by insulin in obesity and glucose intolerance. Europ J Clin Invest 9: $129-135$

6. Ebert R, Creutzfeldt W (1980) Reversal of impaired GIP and insulin secretion in patients with pancreatogenic steatorrhea following enzyme substitution. Diabetologia 19: 198-204

7. Verdonk CA, Rizza RA, Nelson RL, Go VLW, Gerich JE, Service FJ (1980) Interaction of fat-stimulated gastric inhibitory polypeptide on pancreatic alpha and beta cell function. J Clin Invest 65: $1119-1125$

8. Sarson DL, Kopelman PG, Besterman HS, Pilkington TRE, Bloom SR (1983) Disparity between GIP and insulin responses in obese man. Diabetologia 25:386 -391

9. Pederson RA, Brown JC (1976) The insulinotropic action of gastric inhibitory polypeptide in the perfused isolated rat pancreas. Endocrinology 99:870-875

10. Creutzfeldt W, Talaulicar M, Ebert R, Willms B (1980) Inhibition of gastric inhibitory polypeptide (GIP) release by insulin and glucose in juvenile diabetes. Diabetes 29: 140-145

Professor Werner Creutzfeldt

Medizinische Universitätsklinik

Robert-Koch-Strasse 40

D-3400 Göttingen

FRG

\section{Reply from the authors}

Dear Sir,

In our recent paper [1] we examined the acute effects of co-ingestion of fat on the post-prandial metabolic responses to either rapidly or slowly absorbed carbohydrate. Although the co-ingestion of fat resulted in a significant flattening of the post-prandial glucose curves, the insulin responses were not significantly reduced, suggesting that the insulin response to a given glucose concentration was potentiated in the presence of fat. The GIP responses to both carbohydrates were greatly stimulated by the presence of fat. In order to investigate further the possible role of GIP in the entero-insulin axis, a 5-g bolus of glucose was injected intravenously after the slowly-digested carbohydrate in the presence or absence of fat. This was sufficient to result in a 3-mmol/1 rise in plasma glucose and to provoke a marked increase in the insulin response $(50 \mathrm{mU} / 1)$. However, despite the five-fold higher circulating GIP levels, the insulin response to glucose was not increased further in the presence of fat.

Although these results do not exclude the participation of GIP in the entero-insulin axis, the point we wanted to make is that, under the conditions of our experiment, oral fat was clearly shown to induce a marked increase in GIP reponse to an oral carbohydrate load, but that this was not shown to be associated with an increase in insulin release to a subsequent intravenous glucose pulse. It was certainly not the result we had anticipated and forced us to examine alternative explanations for the potentiation of glucose-induced insulin secretion in the presence of fat reported by other groups. Careful examination of these studies indicates a number of potential confounding factors:

1. Although the studies cited by Creutzfeldt [2] show an association between fat-stimulated GIP secretion and the potentiation of glucoseinduced insulin secretion, they do not prove that the two phenomena are linked causally.

2. A dissociation between fat-stimulated GIP secretion and glucose-induced insulin secretion has also been observed by Sarson et al. [3]. They showed that the insulin response seen after oral fat and intravenous glucose was considerably smaller than that after oral glucose despite the GIP concentrations being somewhat higher in the former case and the blood glucose levels being similar in both.

3. Experimental designs differ: in all of the studies showing an association between fat-stimulated GIP secretion and glucose-induced insulin secretion food was present in the gut only when fat was administered, since the carbohydrate was given intravenously. In our study, since carbohydrate was administered orally, food was in the gut in both test situations ( $\pm \mathrm{fat}$ ) with a superimposed stimulus of the $5 \mathrm{~g}$ intravenous glucose bolus, making it, in our view, closer to the true physiological situation of eating. It raises the possibility that the presence of food in the gut per se may be the critical factor in creating the hormonal (or neural) conditions whereby insulin secretion is able to be potentiated when glucose levels are raised intravenously.

4. The time-course of potentiation of insulin secretion may be important. It is possible that any potentiation of glucose-induced insulin secretion occurs early after eating commences, in which case our intravenous injection of the 5 -g glucose bolus would have been too late for an effect to have been evident. However, this time point was chosen because circulating GlP levels did not reach their maximum until $1 \mathrm{~h}$ after fat ingestion.

Finally we must apologize to Creutzfeldt and co-workers for not having referenced their major contributions to this field of research.

Yours sincerely,

K. O'Dea, G. Collier and A. McLean

\section{References}

1. Collier GR, McLean A, O'Dea K (1984) Effect of co-ingestion of fat on the metabolic responses to slowly and rapidly absorbed carbohydrate. Diabetologia 26:50-54

2. Creutzfeldt W (1984) GIP and the metabolic response to carbohydrate and fat. Diabetologia: 27: 484 (Letter) 
3. Sarson DL, Kopelman PG, Besterman HS, Pilkington TRE, Bloom SR (1983) Disparity between GIP and insulin responses in obese man. Diabetologia 25:386-391

\section{K. O'Dea}

Department of Medicine

Repatriation General Hospital

Heidelberg

Victoria 3081

Australia

\section{Glucagon and insulin hypoglycaemia}

\section{Dear Sir}

In their recent report Lager et al. [1] have tested the hypothesis that blunted responses of plasma glucagon to hypoglycaemia in patients with Type 1 (insulin-dependent) diabetes wholly account for their impaired rates of plasma glucose recovery. They conclude that replacement of glucagon in sufficient quantities to normalize portal plasma venous glucagon concentrations does not restore normal glucose counter-regulation in Type 1 diabetes mellitus.

For several reasons these conclusions appear to be questionable. First, recalculation of overall gicose recovery rate from their Figure 1 indicates that the diabetic patients examined after glucagon replaceinent had values greater than those of non-diabetic controls 0.025 vcrsus $0.017 \mathrm{mmol}^{-1} \mathrm{I}^{-1} \cdot \mathrm{min}^{-1}$ ). Secondly, the difference in plasma glucose concentration between glucagon-infused diabetic patients and non-diabetic controls soon after the end of the insulin infusion appears to be negligible, i.e. approximately $0.2 \mathrm{mmol} / 1$. Thus, Lager et al. have shown not only improvement but full normalization of glucose counter-regulation following glucagon replacement in the diabetic patients examined under the experimental conditions of their study.

However, they have replaced glucagon only after the end of the insulin infusion and not in the very early phase of plasma glucose fall [2], as would seem more appropriate, since plasma glucagon increases significantly in response to trivial decrements in plasma glucose [3] and glucagon has powerful effects in the prevention of hypoglycaemia [4]. Thus, the study by Lager et al. shows that supra-physiological increases in plasma glucagon after severe insulin-induced hypoglycaemia in diabetes mellitus succeed in restoring normoglycaemia, but cannot address the question of whether loss of A-cell response to hypoglycaemia accounts totally for disrupted counter-regulation in diabetes.

Clearly, in addition to loss of plasma glucagon responses, blunted responses of other hormones, such as plasma adrenaline, noradrenaline, growth hormone and cortisol [5], contribute to impaired counterregulation in diabetes. Finally, in diabetic patients with even modest antibody binding [2], inappropriate hyperinsulinaemia is an additional factor in impairment of counter-regulation [5].

Yours sincerely,

Geramia B. Bolli

Istituto Patologia Medica Universitá

Via Enrico dal Pozzo

I-06100 Perugia, Italy

(see below for References)

\section{Reply from the authors}

Dear Sir,

The main point raised by Dr. Bolli is whether infusion of glucagon at a rate sufficient to produce physiological levels in the portal blood during experimental hypoglycaemia leads to a complete or only partial normalization of the glucose recovery process in Type 1 diabetes. If a complete normalization is seen, this would support the concept that the impaired glucose recovery can be ascribed to the insufficient glucagon release. Bolli et al. have recently suggested this to be the case [2] and they have now also interpreted the results of our study [1] to support this. We feel, however, that our results show that glucagon infusion certainly improves, but does not completely normalize, the recovery process.

This discrepancy in the interpretation of our results depends on how the glucose recovery rate is calculated. Dr. Bolli has calculated the overall recovery rate, i.e., the increase in glucose from the end of the insulin infusion to the end of the observation period [1, Fig. 1] divided by the time $(140 \mathrm{~min})$. We did not calculate our data in this way since we feel that it is not appropriate and may, in fact, be distinctly mislcading since it docs not take into account the various aspects of the recovery process as outlined below.

The impairment in glucose recovery in normal Type 1 diabetic patient following intravenous insulin infusion is mainly due to two $a b$ normalities [1, Fig. 1]; in contrast to non-diabetic subjects, glucose levels continue to decline for some time even after the insulin infusion is stopped; and the initial, rapid phase of recovery is markedly attemuated (15 min after nadir, glucose increased by $1.1 \mathrm{mmol} / \mathrm{l}$ in the control subjects but only by $0.4 \mathrm{mmol} / 1$ in the diabetic patients). The later phase ( $15 \mathrm{~min}$ and later after nadir) is, however, similar ( 0.015 versus $0.013 \mathrm{mmol} \cdot \mathrm{l}^{-1} \cdot \mathrm{min}^{-1}$ in control and diabetic subjects, respectively, using the same calculations as Dr. Bolli).

It is quite clear that glucagon infusion prevented a decline in the glucose levels after the insulin was stopped. Thus, glucagon completely normalized this abnormality documenting its importance as a counter-regulatory hormone. However, the rapid increase after the nadir, characteristic of normal subjccts $(+1.1 \mathrm{mmol} / \mathrm{l})$, was still clearly attenuated and essentially unchanged in the diabetic patients even when glucagon was infused $(+0.4 \mathrm{mmol} / 1)$ and high physiological portal levels likely to have been present. Consequently, this part of the glucose recovery process was not normalized.

The high overall recovery rate calculated by Dr. Bolli in the glucagon-infused diabetic patients is mainly due to the presence of high glucagon levels throughout the observation period [1, Fig. 3] even at a time when the free insulin levels were normal clearly a non-physiological over-compensation which we also pointed out (p.341, paragraph 3). Even so, the glucose recovery rate was less than half of that occurring shortly after nadir in the control subjects $(0.033$ versus $0.073 \mathrm{mmol} \cdot 1^{-1} \cdot \mathrm{min}^{-1}$, respectively) when similar portal glucagon levels should have been present.

Taken together we feel that our interpretation of the data is the most appropriate at the present time, i.e., glucagon clearly plays an important role, but it is not the only factor accounting for the attenuated recovery from hypoglycaemia in Type 1 diabetes. We are glad that Dr. Bolli now also seems to agree with the complexity of glucose counter-regulation in diabetes and the importance of other factors than glucagon.

Yours sincerely,

I. Lager and U. Smith

\section{References}

1. Lager I, Von Schenck H, Smith U (1984) Improved but not normalized glucose counter-regulation during glucagon infusion in Type 1 (insulin-dependent) diabetes. Diabetologia 26:337-342

2. Bolli $G$, De Feo P, Compagnucci $P$, Cartechini $M G$, Angeletti $G$, Santeusanio F, Brunetti P, Gerich J (1983) Abnormal glucose counter-regulation in insulin-dependent diabetes mellitus: interaction of anti-insulin antibodies and impaired glucagon and epinephrine secretion. Diabetes 32: 134-141

3. Bolli G, Gottesman I, Cryer P, Gerich J (1984) Glucose counterregulation during prolonged hypoglycemia in normal man. Am $J$ Physiol (in press)

4. Unger RH (1983) Insulin-glucagon relationships in the defense against hypoglycemia. Diabetes 32: 575-583

5. Bolli GB, Dimitriadis GD, Pehling GB, Baker BA, Haymond MW, Cryer PE, Gerich JE (1984) Abnornal glucose counterregulation after subcutaneous insulin in insulin-dependent diabetes mellitus: exaggerated hypoglycemia and rebound hyperglycemia; role of multiple counterregulatory hormone deficiences and abnormal plasma insulin kinetics. N Engl J Med 310: 1706-1711

Drs. Ibe Lager and UIf Smith

Department of Medicine II

Sahlgren's Hospital

University of Göteborg

S-413 45 Göteborg

Sweden 